\title{
Effective and Secure E-Governance Model of Haryana
}

\author{
Jitender Singh, Bright Keswani, Ashish Chaturvedi
}

\begin{abstract}
In today's time, e-governance is not only in demand but also trendy. While watching the dream of "Digital India" our Prime Minister Narendra Modi Ji aimed at various goals and the application of ICT (information and communication technology) was one of them. This exchange of information and communication technology is a necessity not only to renew the governmental processes involved in the functioning of government services but also to integrate various stand-alone systems, to improve interactions, for greater convenience, and in cooperating the flow of information and services with different users at much faster rate. Implementation of e-governance aims at crystal-clear government, resulting in the saving of cost and time at providing and receiving services by the government and public respectively, reduction in corruption, strengthening citizen and economic growth . Our operative focus took in six main sections: glimpses on the impacts of e-governance, need for implementing this action, e-governance model, confrontation of challenges, Design and Implementation, emergence of various projects under this one roof and practical recommendations. Every unbiased coin has two different sides so as a by-product in this case also, there are some deeper issues which become weak when it comes to practical guidance, clarity, perplexed positivism regarding this technology. Haryana has empowered e-government research by the intention of penetrating its loop holes such as the institutional factors particularly pressures of competition and time, inefficient delivery of public services, deprivation of quality services - that may restrict the development of e-government as a unified research.
\end{abstract}

Keywords: E-Governance; Revenue Court; Saral; Justice Delivery System

\section{INRODUCTION E-GOVERNANCE MODEL}

The main target of e-governance is basically the peculiar use of ICT in order to satisfy three main groups and that are: government, citizens and businesses/interest groups.

These are divided in two categories: INTERNAL and EXTERNAL. The former one's strategic objective is to focus on citizens and business groups while latter one focuses on government.

Revised Manuscript Received on July 22, 2019

Jitender Singh, Research Scholar, Department of Computer Science \& Engineering, Suresh Gyan Vihar University, Jaipur, India

Dr. Bright Keswani, Professor, Computer Science, Department of Computer Science \& Engineering, Suresh Gyan Vihar University, Jaipur, India

Dr. Ashish Chaturvedi, Professor, Computer Science, Calorx Teachers' University Ahmedabad, India

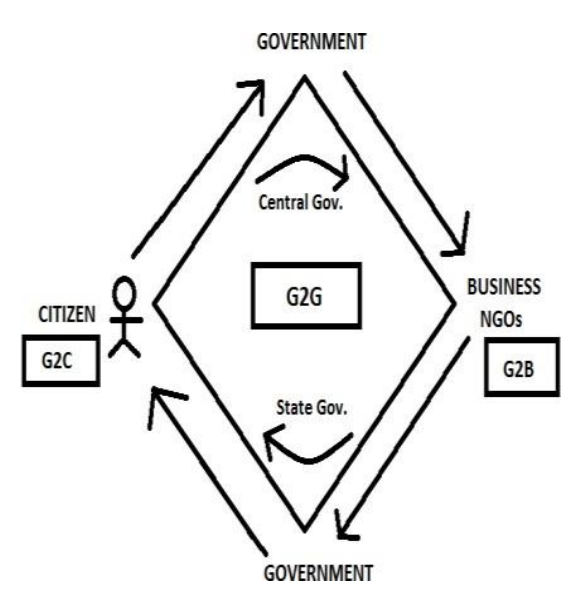

Figure: Interaction among main groups via e-governance.

E-governance is not limited to a website of government over internet, its significance is more than that. What kind of services be offered in future? How it is implemented? What are the possibilities of its success in future? All the answers to these questions are hidden in the model itself. [7]

An international e-business research consultancy firm called Gartner, has formulated a four-phase e-governance model which is as follows:

PHASE 1: INFORMATION - In the first phase, egovernance is all about giving services to citizens and business group i.e. G2C and G2B where external public is being the center. All the government information is easily accessible; all the schemes and services are properly described and hence shows transparency to all the public. Internally $\mathrm{G} 2 \mathrm{G}$ is all about circulating information through internet from one government to another.

PHASE 2: INTERACTION - In the second phase, there is interaction between the government and the common public via various mediums, be it e-mail, asking queries over various search engines, knowing status of various forms or applications and in fact all this work can be done 24/7 with the assurance of getting responses as well. Waiting for the opening of various counters and grabbing information from that has now been avoided. Most of the intake processes are now done digitally however rest of the transaction part i.e. paying fee is done manually but that also is not really a complex process.

PHASE 3: TRANSACTION - In this phase, customer is the first priority and their convenience is the main goal however there is a bit complexity at the technological part. All the transactions can be carried out without going to any counter/office.

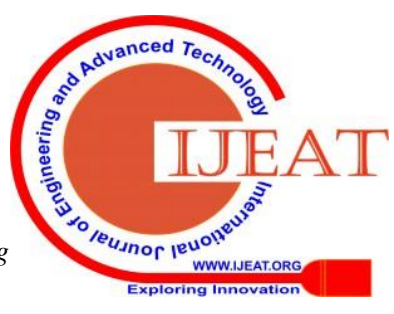




\section{Effective and Secure E-Governance Model of Haryana}

Filing income tax, extending/renewal of licenses, filing property tax, visa and passports and online voting are some of the examples of online services. Here complexity occurs when it comes to privacy and security issues like digital (electronic) signatures are mandatory to execute any legal transfer of services. On the other hand the government is starting with e-procurement applications for the business groups. For moving a step towards cashless and paperless world, government needs to create new laws that provides legal certification and good services to the users. By making whole process online including all types of payments, digital signatures will result in saving time, cash and paper.

PHASE 4: TRANSFORMATION - This phase is about transforming all the service counters into one single (digital) counter where the information can be easily accessible. Now that $\mathrm{G} 2 \mathrm{C}$ and $\mathrm{G} 2 \mathrm{~B}$ services are accessible in hands through that one single platform. The difficult part arises in reaching this goal is mainly because of the internet; adapting such a vast change like in various processes, their culture, responsibilities within the government i.e. G2G. In fact people working in different government departments have to work simultaneously in the most efficient way to make this system keep going and most importantly it should be smooth enough that will help in cost savings and provide satisfaction to the customers at its best possible level.

Bringing e-governance into play has never been an easy task and will never be. This change disseminate gradually, some services has already turned digitally and rest will be sooner move towards it. According to Gartner, e-governance will grow slowly according to the four-phase maturity model which is shown below:

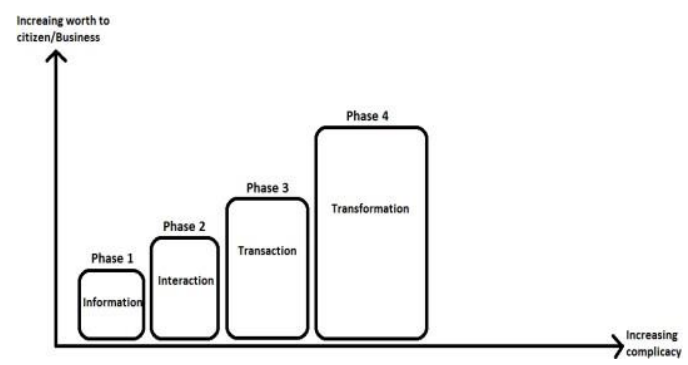

Figure: Four-phase Maturity Model

\section{DESIGN AND IMPLEMENTATION}

\section{APPROACH:}

The crucial step in planning e-governance lies in 3 main steps: Think BIG

Start Small

Scale Fast

The approach is to investigate how e-governance policy is being thought, what the strategy that is to be applied is and what are the projects that came under e-governance. If the vision is not only limited to present but reaches to the future also i.e. a long term vision wherever be seen always results in success. The Gartner's model mentioned above can be seen as a reference for government to categorize a project that where it fits in, out of that four-phases. Strategy before any task is must because it always highlights the knowledge behind the project. An e-governance strategy is inevitable to achieve the desired goal and the goal is to strategise every e-policy in a manner such that it results in the favor of citizens as well as for the government.

The model interprets that government has now attracted towards an ICT and ambition level for each of the egovernance policy is different in every aspect. Only some Western countries have a clear vision of e-governance. So the ultimate task is to check the ambition level in most of the developing countries. So now the case varies between developed and developing countries because of the uneven accessibility of internet in both of the categories. That's why strategy should deal with these variations and restrictions.

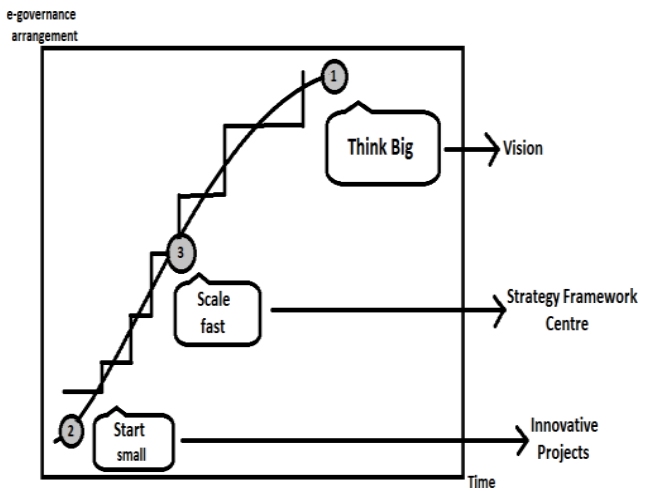

Figure: Approach to implement e-governance

\section{E-Governance MOdel OF HARYANA}

To provide any of the service of Revenue court cases, click on the link 'Revenue Court Cases' has given in the transactional services area of home page of user. Figure-1 shows that screen.

E-governance in Haryana was not only strenuous but also need of the state and its implementation was really impactful and remarkable for all; be it farmer, businessman, trader or service provider; it was the aid to the day to day problem of their lives. State government thought of a plan which not only can speed up the delivery of the services by the various departmental offices but also made it convenient and hasslefree. Large number of initiatives were taken in the era of egovernance. Reliable efforts have been put at multiple levels to improve and manage the delivery of public services and most importantly to simplify the method of accessing them. E-governance has done so much amendments from computerization of government departments to taking initiatives that shows the originality and transparency of the government deeds. Dreaming of wireless infrastructure was not possible until the government launched BHARATNET; this is a National Optic Fiber network programme which has laid optical fiber reaching 5,620 villages [5]. This network shall ensure provision of $100 \mathrm{mbps}$ internet connectivity to all Gram Panchayats [5]. In the recent past, for digital infrastructure, Haryana has taken various remarkable initiatives to increase digital delivery of services and to empower the citizens. Various e-governance projects that are undertaken by the state government are :CM Window, eBhoomi , e-Payment , e-Registration , e-Refund , e-Filling , e-Tendering , e-Disha , e-Tourism, e-Ticketing etc. 
CM Window Haryana is basically a monitoring system and public grievances redressal which is launched to confront every public problem with ease and to encapsulate the transparency of the government. Selling of land becomes easy because of e-boom as it sells directly to the government. Eservices for traders such as e-payment, e-registration, erefund, e-filling, e-tendering etc. are available at www.haryanatax.gov.in. [5] e-Disha (e-district Haryana) is an IT-based electronic medium between the government and the citizens that access the general public services on timely basis. Awareness is important so that every citizen can avail government services so as a part of nationwide 100-day special campaign, promotion of digital and cashless transactions were done by organizing, 'Digi Dhan Melas' in the state. To bring government services to the doorstep of the citizens, government has setup 5500 ATAL SEVAKENDRAS, out of which 4000 are located in villages [5]. This has made the delivering of services more simple and comfortable for both citizens and government.

\section{RESUlTS AND FUTURE WORKS}

E-governance has played a crucial role in empowering India digitally. It has come a long way in bridging the technological obstacles while channelizing the public services through various e-channels and making it possible to develop a single unbiased platform for all the citizens. Its impacts are seen more in developing countries like India and Qatar where promotion of e-governance have shown remarkable strides. The issues and challenges need to be penetrated to make India fully digital and by understanding the significance of egovernance, this dream is not really far.

Agricultural Sector has always been the pride of India because the main occupation in India is agriculture. Essential importance should be given to the agricultural sector which will not only increase the economy of our country but also make it a developed country which all have been dreaming for so many years.

So, good ICT infrastructure should be provided in terms of better connectivity, electricity etc. Despite of having immense population, India is a poor country having poverty and corruption as its two black holes. And the only solution to this problem is Education and e-learning is just another savior. To raise the economy, ICT literacy is required in which these two factors can help in making the path smoother. Awareness is what we have discussed as the toughest challenge especially for the people living in villages. Literacy is a prominent factor for the success of implementing egovernance. E-learning or E-education provides social networks platform through which accessibility of services become easy across urban and rural areas of India. This will lead to create interest among social media users and will bring people of similar interest together even though they are far from distance. Further establishing a knowledge sharing portal to exchange information about e-governance would be even better.

Some basic recommendations to improve the drawbacks of egovernance are:

- Tracking status of any application is facilitated by the web portal.

- Tracking status of any application is also facilitated through SMS.
- Based on Service Delivery Index, tracking the performance of department is also available.

- One window platform for citizens now can apply for 102 services pertaining to 12 departments.

- $\quad$ Single platform is being made for the citizens to avail benefits of 181 Schemes pertaining to 14 departments.

Establishing more simple and easygoing procedures and services, Channelizing the needs of user-friendly technical solutions as well as securing all the legal procedures at government level, Bringing together all the e-governance strategies and solutions developed by the State as well as the Central government. The problem of having difficulty regarding the mind-set of the people should be discussed in a constructive manner by telling them the approach of egovernance. Competent training and support at every step should be given. All this will lead to overcome the obstacles in the path of e-governance.

\section{REFERENCES}

1. Volume 1, issue 2, Dec 2016 ISBR Management Journal Implementation of E-Governance : Issues and Challenges * Nasrulla khan $\mathrm{k} \quad * *$ N.AnithaKumari http://www.isbr.in/journals/volume1-issue2-journal2.pdf

2. Gyandoot: E-Governance Project in India, Rridhee Malhotra https://medium.com/@ rridhee/gyandoot-e-governance-project-in-indi a-9664acf38e9d

3. http://www.doingbusinessinmaharashtra.org/egovernance_policy.aspx

4. System for Computerised Registration - SCORE* Saurabh Gupta, Sr Technical Director \& State Informatics Officer NIC Technology Bhawan, Bailey Road, Patna, Bihar Bihar State Centre, Patna siobih@nic.in N K Prasad, Sanjay Kumar https://www.nisg.org/files/documents/B05040003.pdf

5. Department of Information Technology \& Communication, Haryana http://haryanait.gov.in/en

6. e-Services (SARAL https://haryana.gov.in/project/saral-haryana/index.html

7. E-Governance and Developing Countries RESEARCH REPORT No. 3, April 2001, Michiel Backus http://www.bibalex.org/Search4Dev/files/288383/119334.p f 